\title{
Erratum to: Oceanic residents, neritic migrants: a possible mechanism underlying foraging dichotomy in adult female loggerhead turtles (Caretta caretta)
}

Hideo Hatase $\cdot$ Kazuyoshi Omuta •

Katsumi Tsukamoto

Published online: 9 April 2010

(C) Springer-Verlag 2010

Erratum to: Mar Biol

DOI 10.1007/s00227-010-1413-9

Unfortunately, Fig. 1 of the original article was published without open and solid circles which should be adjacent to Oceanic $(n=27)$ and Neritic $(n=75)$, respectively. The correct figure is given below.

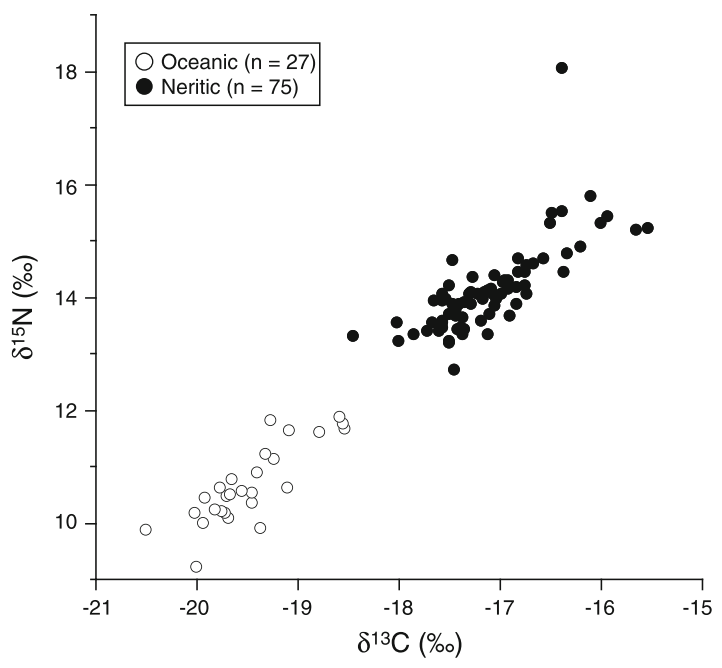

The online version of the original article can be found under doi:10.1007/s00227-010-1413-9.

H. Hatase $(\bowtie) \cdot$ K. Tsukamoto

Ocean Research Institute, University of Tokyo,

1-15-1 Minamidai, Nakano, Tokyo 164-8639, Japan

e-mail: hatase@ori.u-tokyo.ac.jp

K. Omuta

Yakushima Sea Turtle Research Group, 489-8 Nagata,

Yakushima, Kagoshima 891-4201, Japan 